\title{
A rural trip through time
}

Last update: 27 February 2017

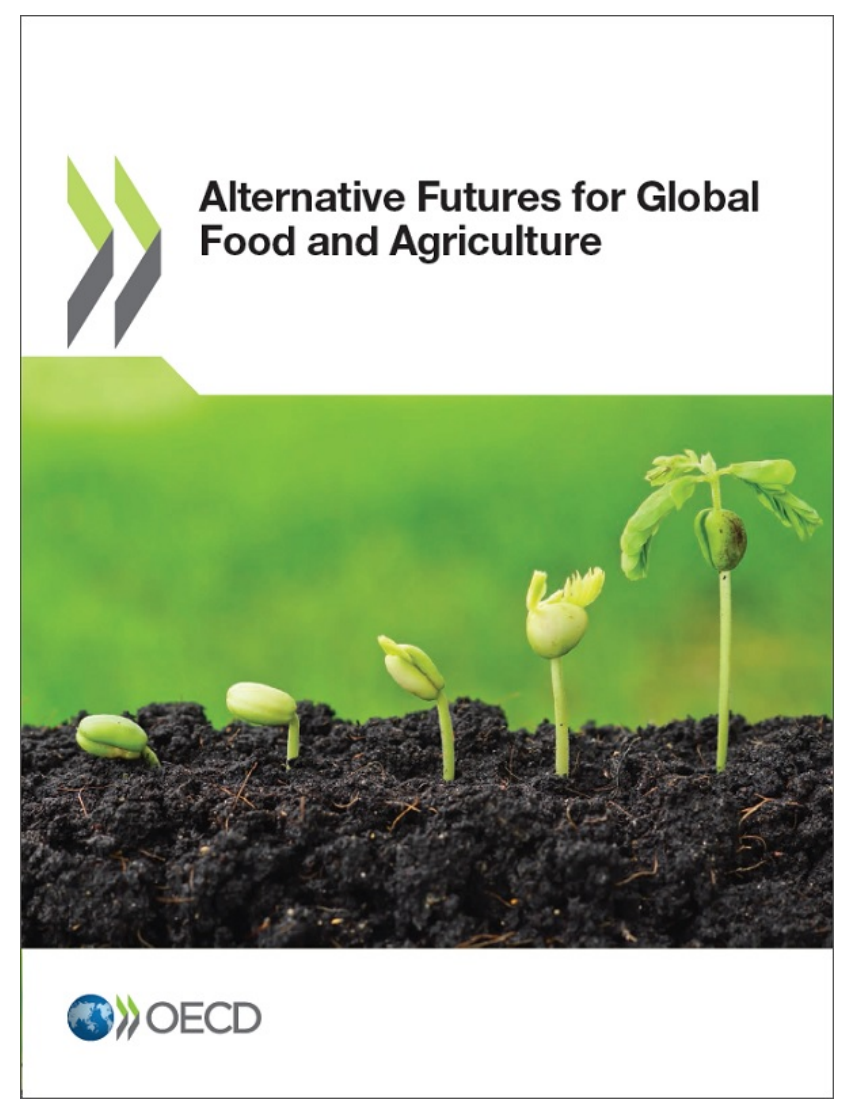

Imagine travelling through time, not as Stephen Hawking would, through wormholes into a new dimension, but rather just to see how farming might look several decades from now. How policy makers and farmers might appreciate such foresight.

Alternative Futures for Global Food and Agriculture proposes to do just that, by exploring three potential "futures" which our food and agricultural systems may face in the lead up to 2050. Will global food systems be able to feed nine billion people without destroying sensitive ecosystems or social coherence? Can agricultural productivity keep up with rapidly increasing demand while facing significant and unpredictable challenges such as climate change, livestock diseases and other factors which escalate production costs? Will farming be a profitable business in the coming decades, and help rural areas to develop? These are just some of the key questions the study helps to address.

The many uncertain and ever-changing factors surrounding these questions can pose immense challenges for the development of long-term policy and industry 
strategies to address them. Rather than present forecasts or projections, Alternative Futures for Global Food and Agriculture sets out different possible scenarios that take political, economic, technological and other "known unknowns" into account, opening the way for the development of appropriate strategies for both governments and businesses.

The three potential "futures" explored are: "individual, fossil fuel-driven growth", which portrays a world driven by the strong focus of individual countries and regions on their own economic growth, and relatively minimal emphasis by governments or their citizens on environmental or social challenges; "citizendriven, sustainable growth", in which consumers and citizens drive their governments to emphasise environmental and social protection above all, and in which global co-operation is relatively limited; and, lastly, "fast, globally-driven growth", characterised by a strong focus on international co-operation to achieve economic growth, and in which environmental issues receive less attention. Though each of these alternatives suggests very different outcomes, they all point to the need for policies that are sufficiently robust, comprehensive and versatile to respond to the challenges ahead.

\section{References}

Alternative Futures for Global Food and Agriculture http://dx.doi.org/ 10.1787/9789264247826-en 